\title{
Rupture of Cerebellar Arteriovenous Malformation in Pregnant: A Case Report
}

\author{
Kariman Ghazall ${ }^{1,3 *}$, Jihad Alhassan ${ }^{1,2}$, Eva koulaymi ${ }^{1}$ and Samir Zoubeir ${ }^{3}$ \\ ${ }^{1}$ Department of Obstetrics and Gynecology, Lebanese University, Lebanon \\ ${ }^{2}$ Head of department of obstetrics and gynecology, Zahraa Hospital University Medical Center, Lebanon \\ ${ }^{3}$ Department of Obstetrics and Gynecology Makassed General Hospital, Lebanon \\ ${ }^{4}$ Head of department of Neurosurgery, Makassed General Hospital, Lebanon
}

Submission: March 18, 2021; Published: March 22, 2021

*Corresponding author: Kariman Ghazal, Department of Obstetrics and Gynecology, Lebanese University, Lebanon and Makassed General Hospital, Lebanon

\begin{abstract}
Stroke is an extremely rare event during pregnancy with the incidence ranging from 10 to 34/100,000 deliveries. Compared to non-pregnant women, stroke rates are lower during the antepartum period, 9-fold higher in the early peripartum period and 3-fold higher in the early postpartum period. Brain Arteriovenous malformations (AVM), are type of hemorrhagic stroke, and are abnormal communication between parts of cranial arterial and venous systems. Following AVM rupture during pregnancy, maternal mortality was $28 \%$ and fetal mortality was $14 \%$. We report the case of a 37-week-pregnant woman who presented with decreased level of consciousness caused by ruptured cryptic cerebellar AVM, treated surgically by cerebellar ventriculostomy followed by cesarean section.
\end{abstract}

\section{Introduction}

The world health organization (WHO) defines stroke as: "a clinical syndrome of rapidly developing clinical signs of focal or global disturbance of cerebral function, lasting more than $24 \mathrm{~h}$, or leading to death, with no apparent cause other than vascular origin" $[1,2]$. It is an extremely rare event during pregnancy with an incidence ranging from 10 to $34 / 100,000$ deliveries [3-5]. A recently conducted cohort in England showed that, stroke rates are lower during the antepartum period, 9-fold higher in the early peripartum period and 3 -fold higher in the early postpartum period, compared to non-pregnant women [6].

Brain Arteriovenous malformations (AVM) are abnormal communication between parts of cranial arterial and venous systems with the lack of a true nutritive and absorptive capillarybed [7]. AVM is relatively uncommon; their prevalence ranges between $0.01-0.5 \%$ [8] and clusters between $3^{\text {rd }}$ and $5^{\text {th }}$ decade [9-11]. In more than one half of the cases even during pregnancy, it presents with hemorrhage [9-12]. Even if the rupture of an intracranial arteriovenous malformation (AVM) in pregnancy is a rare, it may have fatal consequences [13]. Arteriovenous malformations (AVMs) are the most common cause of intraparenchymal hemorrhage (IPH) [14]. The rate of intracranial hemorrhage from AVM was reported to $8.1 \%$ per pregnancy, higher than the annual hemorrhage rate of AVM in female patients $[15,16]$. Maternal mortality is estimated to $28 \%$ and fetal mortality is $14 \%$, Following AVM rupture during pregnancy $[15,16]$. Historically, surgical treatment did achieve great results in ruptured AVMs in pregnant women [15-19]. Even so, while managing AVM during pregnancy, 2 problems exist: first, the significant morbidity and mortality of intracerebral hemorrhage due to AVM or aneurysm during pregnancy and puerperium [20], and, second, is the poorly defined natural history of AVM during pregnancy [21,22], which hinders development of definite guidelines for management of AVM during pregnancy [22,23]. Here, we report the case of a 37-week-pregnant woman who presented with decreased level of consciousness caused by ruptured cerebellar AVM, treated by cerebellar ventriculostomy by cesarean section.

\section{Case Report}

A healthy 19 years old G2P0A1, at 37 weeks of gestation, presented to our delivery suite (DS) with altered level of consciousness. The patient had one episode of severe headache 
2 hours prior to presentation, after which she had 3 attacks of projectile vomiting. When she presented, her vital signs were within normal range. Upon examining her, she had a Glascow Coma Scale of 12/15 (Figure 1) with right hemiparesis and right facial muscle twitches. Her labs, hemoglobin, platelets, thyroid function test, liver function test, renal function test were all in normal limits. Dipstick for proteinuria revealed absence of albumin. Twenty minutes later, the patient tuned into pale, moaning, unresponsive to verbal stimuli with a deterioration of Glascow Coma Scale to 8/15; confused, open her eyes to pain, with lower limbs decortication response to pain. She had bilateral reactive pupils on neurological exam with right side hemiplegia and equivocal plantar reflex. CT scan showed a right large right cerebellar hematoma, surrounded by edema, crossing the midline, compressing the brainstem and fourth ventricle without evidence of hydrocephalus, as shown in Figure 2. 20 minutes later, she was intubated as she was tachypneic with abdominal breathing and oxygen saturation of $95 \%$. Urgent MRI of brain revealed a large right cerebellar hematoma, crossing the midline, compressing the brainstem and the fourth ventricle displacing it to the left, with no evidence of obstruction of the cerebrospinal flow (Figure 3).

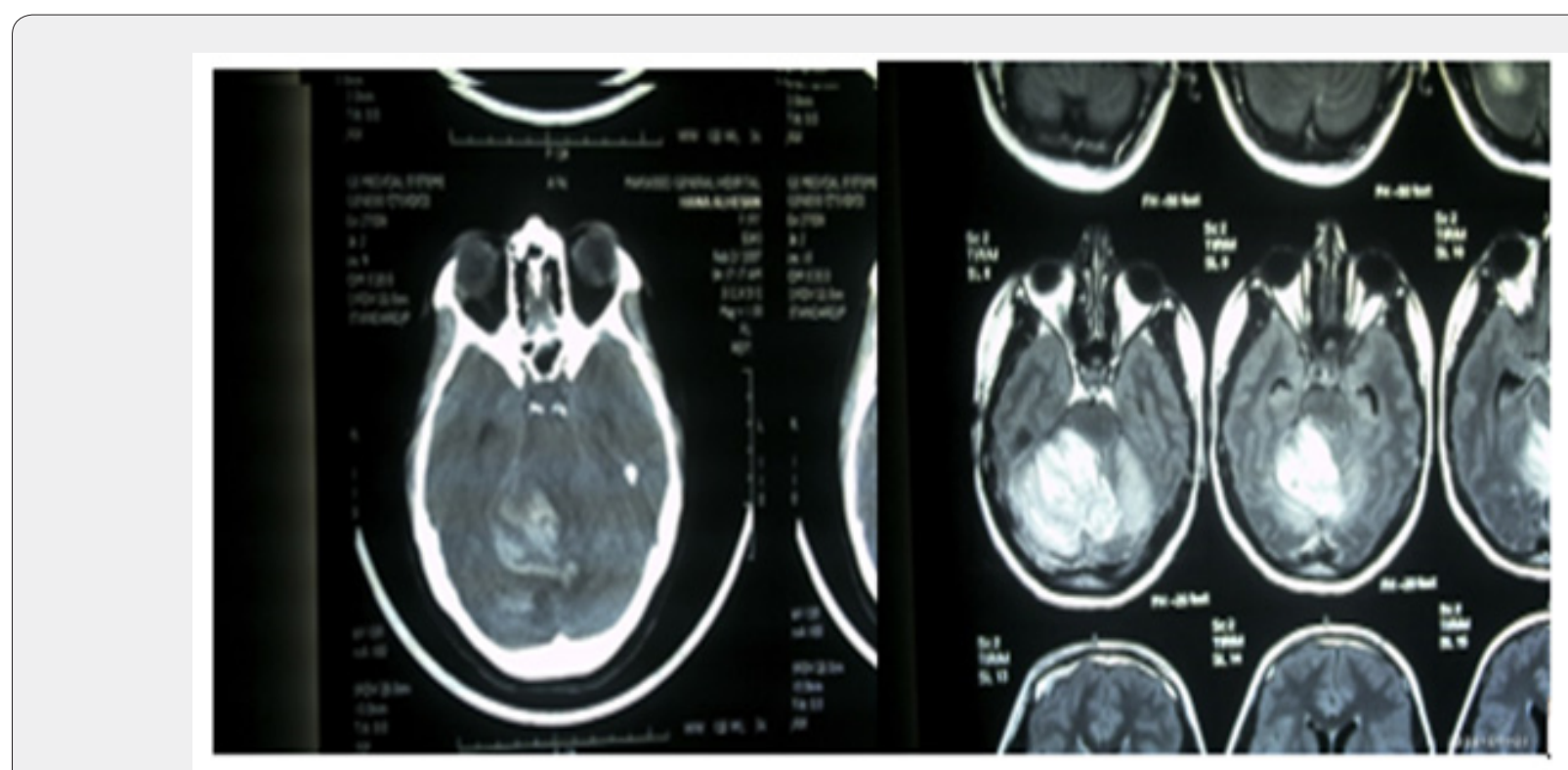

Figure 1: Axial cut of the head CT showing intracerebral haemorrhage.

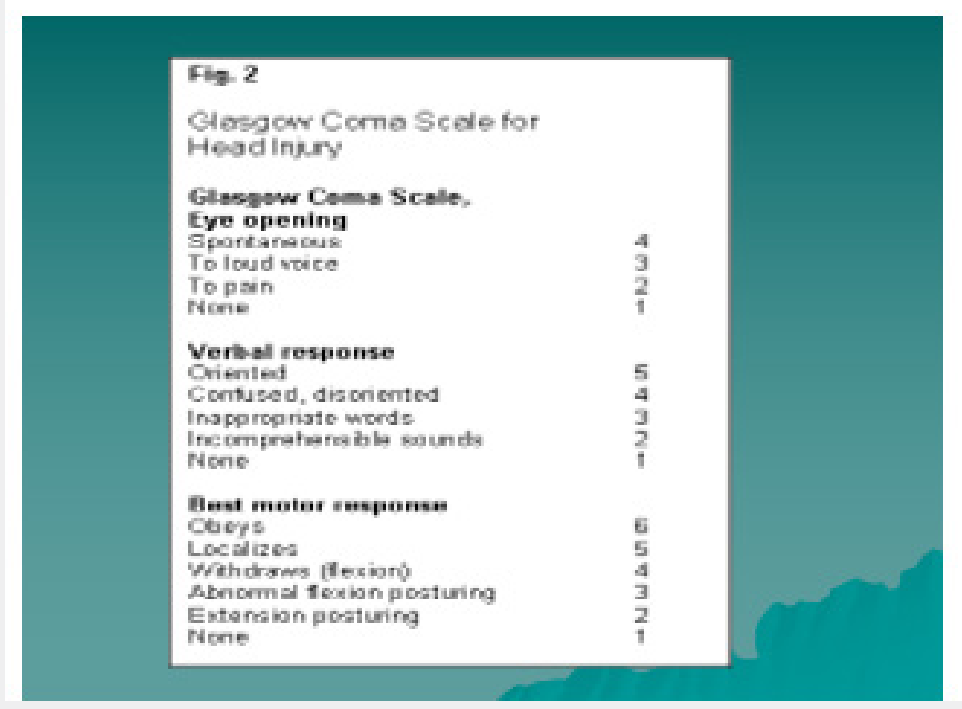

Figure 2: Glascow coma scale for head injury. 


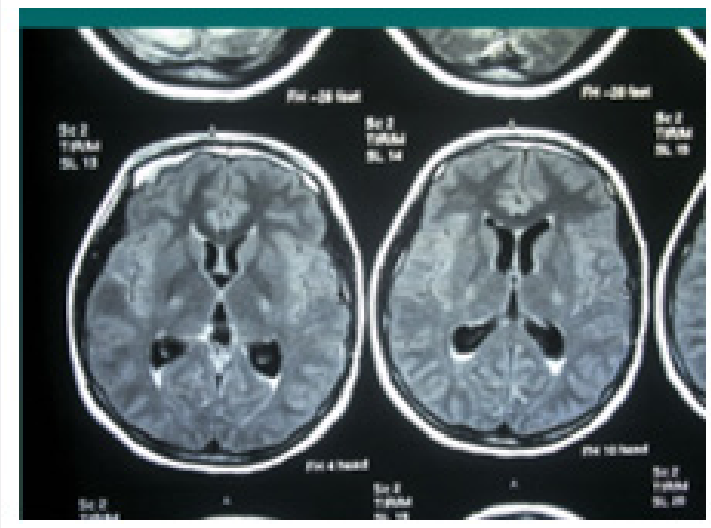

Figure 3: MRI cut revealing posterior fossa and cerebellum hemorrhage.

For these findings, the consulted neurosurgeon decided on urgent right suboccipital craniotomy, followed by evacuation of the right cerebellar hematoma with insertion of right occipital cerebellar ventriculostomy. A low segment cesarean section followed the craniotomy, and a live female was delivered weighing 3100 grams with APGAR 7/9 at 1/5 minutes, respectively. Her postoperative hospital stay is described as follows: initiation of Decadron 4mg IV OD. On the day 2 post operation, she was responsive to verbal stimuli, but with uncoordinated limb movement. On day 9 post operation, she has dysarthria, and staccato speech. She was discharged11 in good clinical condition; the patient had good evolution after the treatment of an uncommon presentation of AVM in an uncommon clinical condition, that is, AVM during the pregnancy.

\section{Discussion}

\section{Physiologic changes in Pregnancy}

Table 1: Variation of the different parameters during pregnancy.

\begin{tabular}{|c|c|}
\hline Parameter & Variation \\
\hline Blood volume & increase \\
\hline Cardiac output & increase \\
\hline Factors I, VII, VIII & increase \\
\hline Parameter & Variation \\
\hline Blood volume & increase \\
\hline Cardiac output & increase \\
\hline Factors I, VII, VIII & increase \\
\hline
\end{tabular}

Pregnancy by itself is a hyperdynamic state; where changes occur in the hemostatic system [24]. There will be a remodeling in blood vessels due to the increase in cardiac output and blood volume while a reduction in wall elastin and collagen resulting in less stiffness and more relaxation. In fact, pregnancy induced hemorrhagic and ischemic complications result in hemodynamic stress. This is due to an increase of the procoagulant factors I, VII, VIII, increase in coagulation inhibitors; antithrombin III, protein $\mathrm{S}$, compression of large vessels and hemodynamic Venous stasis and slow flow. All these factors promote towards a pro-thrombotic state [24-26]. This is shown in the Table 1.

Normally, the blood brain barrier (BBB) prevents extravasation of proteins, sodium and potassium into the extracellular space of the brain. This adjusts local Starling's forces so that the osmotic pressure exerted by ions retained in the vascular compartment opposes transit of water into the brain. Under usual conditions, this prevents vasogenic edema [27]. This is shown in Figure 4. It shown that pregnancy increases BBB permeability in the presence of hypertension, [28]. Effectively, as gestation progresses, MCA flow decreases and CBF decreases [29]. More specifically, to minimize the change in perfusion, $\mathrm{CBF}$ decreases by $20 \%$ in the later stages of pregnancy and posit that vascular resistance falls [30]. This might suggest that the range of cerebral autoregulation changes during pregnancy and the relative hypertension of preeclampsia and eclampsia leads to rupture of vessels at a lower pressure than in the non-pregnant women.

\section{Spontaneous intracerebral hemorrhage}

Nontraumatic intracerebral hemorrhage (ICH) is bleeding into the parenchyma of the brain that may extend into the ventricles and, in rare cases, the subarachnoid space. Each year, approximately 37,000 to 52,400 people in the United States develop an intracerebral hemorrhage [31]. ICH may be classified anatomically as extradural, subdural, subarachnoid or intracerebral. Extradural and subdural hemorrhages are usually related to trauma. Spontaneous subarachnoid hemorrhage is usually caused by aneurysmal rupture. Spontaneous intracerebral hemorrhage in obstetric patients is most often caused by AVM and hypertension. Although hypertensive intracerebral hemorrhage remains the most common causes of intracerebral hemorrhage, underlying vascular abnormalities should always be considered in 
appropriate circumstances because of the high risk of recurrent hemorrhage and to allow optimal treatment option. The worldwide incidence of intracerebral hemorrhage ranges from 10 to 20 cases per 100,000 population and increases with age. Intracerebral hemorrhage is more common in men than women, particularly those older than 55 years of age, and in certain populations, including blacks and Japanese [32-34].

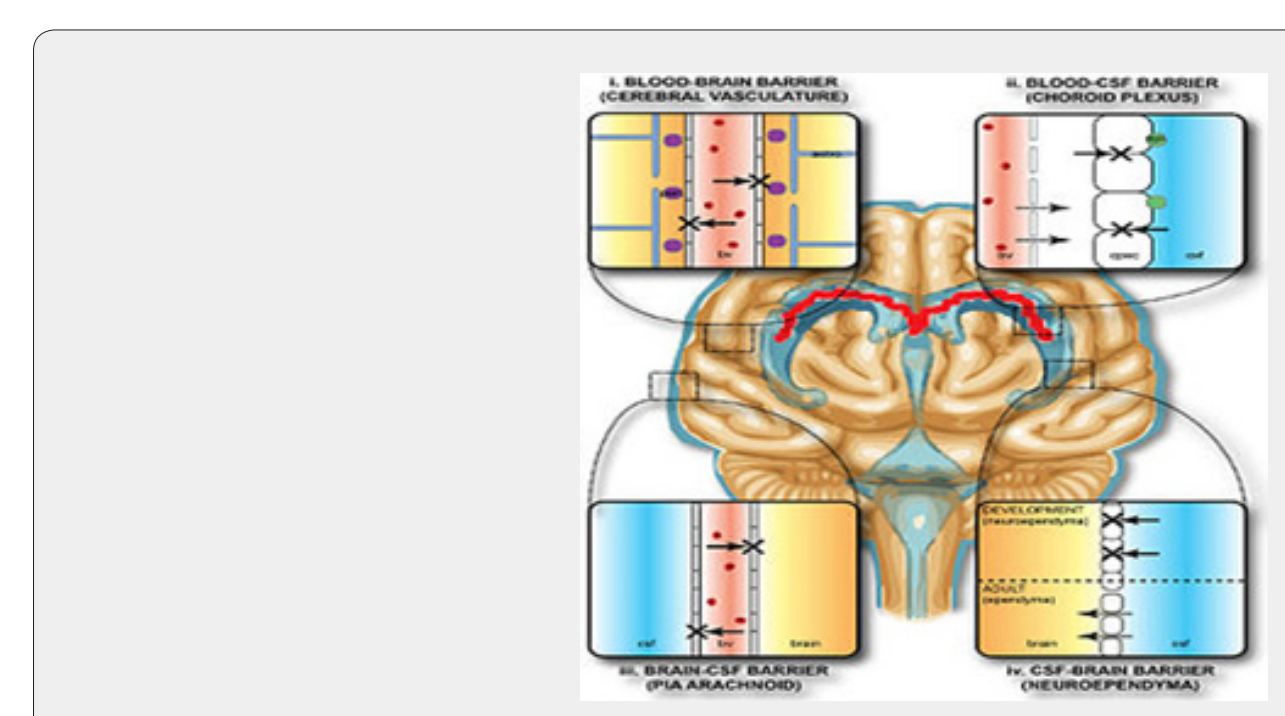

Figure 4: The blood brain barrier (BBB).

\section{Risk factors}

Hypertension is the most important risk factor for spontaneous intracerebral hemorrhage. Other risk factors are excessive use of alcohol, serum cholesterol levels of less than $160 \mathrm{mg} / \mathrm{dl}$, cerebral amyloid angiopathy, arteriovenous malformation, intracranial aneurysm, cavernous angioma, venous angioma, dural venous sinus thrombosis, intracranial neoplasm, Coagulopathy, vasculitis, cocaine or alcohol use, hemorrhagic ischemic stroke [35,36].

\section{Progression of intracerebral hematoma}

As bleeding continues, hematoma expends and disrupts surrounding vessels. Expansion of the hematoma might be associated with acute hypertension, a local coagulation deficit, or both. Initially, intracerebral hemorrhage was considered a monophasic event that stopped quickly as a result of clotting and tamponade by the surrounding regions. This impression is incorrect, as CT scans show that hematomas expand over time. Secondary neuronal injury after intracerebral hemorrhage neuronal death in the region around the hematoma is predominantly necrotic, with recent evidence suggesting the presence of programmed cell death (apoptosis) [37-39].

\section{Neurologic Status at Presentation}

A patient with intracerebral hemorrhage can present with variable signs and symptoms such as decreased level of consciousness, contralateral sensory-motor deficits of varying severity, signs of brain-stem dysfunction, signs of higher level of cortical dysfunction, signs of cerebellar involvement [39].

\section{Outcome}

The mortality rate 6 months after spontaneous intracerebral hemorrhage ranges from 23 to 58 percent. Some factors have been consistently identified as predictive of a high mortality rate: a low score on the Glasgow Coma Scale, large volume of the hematoma, the presence of ventricular blood on the initial CT scan [40].

\section{Diagnosis}

It can be done via CT scan, conventional angiography or MRI $[40,41]$.

\section{Management}

There are 2 main approaches in the management of intracranial hemorrhage. First, evaluation and management in the emergency room intensive monitoring of neurologic and cardiovascular status, the mass effect and intracranial hypertension, ventricular blood and hydrocephalus. Second, evaluation and management for early intubation, neurosurgical consultation, hyperventilation, IV Mannitol, IV catheter, and thrombolytic therapy [42-45].

\section{Surgical Evacuation}

The goals of the surgical evacuation of a hematoma are to reduce the mass effect, to block the release of neuropathic products from the hematoma and prevent prolonged interaction between the hematoma and normal tissue, which can initiate pathologic processes $[42,46]$. Cerebellar hematomas are unique from a surgical perspective because they can be approached without causing substantial damage to higher cortical or primary motor pathways [47-49]. 
Morbidity and mortality are related to compression of the brain stem and are decreased by timely decompression. The best surgical results are in patients with a cerebellar hemorrhage who have an initial score of less than 14 on the Glasgow Coma Scale or large hemorrhages (volume, $40 \mathrm{ml}$ or more). To prevent secondary pathologic processes and limit neural damage and the risk of recurrent bleeding associated with open craniotomy, studies are now focusing on early surgical evacuation with the use of stereotactic and endoscopic approaches [50].

\section{Seizures and Recurrent Hemorrhage}

\section{Aspirin \& effect on ICB}

The prevalence of cerebral AVMs is estimated at 0.01 $0.50 \%$ of the population. AVM is generally present in patients aged between 20 and 40 years, the childbearing age for women. Globally, the natural history of AVMs is poorly understood and even less understood in pregnant patients, because its frequency is rare and changes in the maternal body are complicated during this period [51]. The microsurgical treatment of infratentorial AVMs is decided depending on the surgical expertise and AVM`s location. Infratentorial AVMs are less common than supratentorial ones, occurring for less than $15 \%$ of cases. The initial clinical manifestation is mainly due to bleeding with annual rates three times greater compared with supratentorial lesions. Infratentorial AVMs are most commonly located in the cerebellar hemispheres and are $3-5 \mathrm{~cm}$ in size with arterial nutrition by SCA. The rates of mortality and morbidity are bigger when the AVMs are in posterior fossa and there is clinical presentation because of the proximity to critical structures, brainstem, and cranial nerves. In this case, the patient had good evolution after the treatment of an uncommon presentation of AVM in an uncommon clinical condition, that is, cryptic cerebellar AVM during the pregnancy that has bled and was destroyed by the hemorrhage.

\section{Conclusion}

We achieved good maternal and fetal outcomes in our case. We performed the good approach before cesarean section as the intracerebellar hemorrhage might progress resulting in deterioration in the neurological status of the patient. We also had to know the architecture of the AVM to prevent intraoperative complications during the cesarean section and neurosurgical procedure. Cooperation between neurosurgeons, obstetricians, and anesthesiologists and adequate information about the treatment strategy given to the patients are essential.

\section{References}

1. Trueslen T, Begg S, Mathers C (2012) The global burden of cerebrovascular disease. Cerebrovascular disease 21-06-06.

2. World health organization (2002) The world health report: 2002: reducing risks, promoting healthy life.

3. Jaigobin C, Silver FL (2000) Stroke and pregnancy. Stroke 31(12): 2948-2951.

4. James A, Bushnell C, Jamison M, Myers ER (2005) Incidence of stroke in pregnancy and puerperium. Obstet Gynecol 106(3): 509-516.

5. Lanska D, Kryscios R (1998) Stroke and intracranial venous thrombosis during pregnancy and puerperium. Neurology 51(6): 1622-1628.

6. Tolefac P, Standley N, Minkande J (2018) Spontaneous haemorrhagic stroke complicating severe preeclampsia in pregnancy: a case report in a resource- limited setting in Cameron. BMC pregnancy and child, p. 18.

7. Agarwal N, Guerro JC, Gala NB, Agarwal P, Zouzias A, et al. (2013) Current treatment options for cerebral arteriovenous malformations in pregnancy: a review of the literature. World neurosurg 81(1): 83-90.

8. Choi JH, Mohr JP (2005) Brain arteriovenous malformations in adult. Lancet neurol 4(5): 299-308.

9. FleetWood IG, Steinburg GK (2002) Arteriovenous malformation. Lancet 359(9309): 863- 873.

10. Arteriovenous Malformation Study Group (1999) Arteriovenous malformations of the brain in adults. N Eng J Med 340(23): 1812- 1818.

11. Brown RD, Wieber DO, Torner JC, O'Fallon WM (1996) Frequancy of intracranial hemorrhage as a presenting symptom and subtal analysis: a population-based study of intracranial vascular malformation in Olmsed country. Minesotta J Neurosurg 85(1): 29-32.

12. Hofmeister C, Stapf C, Hartman A, Sciacca RR, Mansmann U, et al. (2000) Demographic, morphological, and clinical characteristics of 1289 patients with brain arteriovenous malformation. Stroke 31(6): 1307-1310.

13. Jemakowicw W, Tomycz L, Ghiasssi M, Singer RJ (2012) Use of endovascular embolization to treat a ruptured arteriovenous malformation in a pregnant woman: a case report. J Med Case Reports 6: 113.

14. Perquin DA, Kloet A, Tans JT, Witte GN, Dörr PJ, et al. (1999) Intracranial arteriovenous malformations in pregnant women. Ned Tijdschr Geneeskd 143(10): 497-500.

15. Trivedi RA, Kirkpatrick PJ (2003) Arteriovenous malformations of the cerebral circulation that rupture in pregnancy. J Obstet Gynaecol 23(5): 484-489.

16. Fujita K, Tsunoda H, Shigemitsu S, Kubo T (1995) Clinical study on the intracranial arteriovenous malformation associated with pregnancy. Nippon Sanka Fujinka Gakkai Zasshi 47(12): 1359-1364.

17. Robinson JL, Hall CS, Sedzimir CB (1974) Arteriovenous malformations, aneurysms, and pregnancy. J Neurosurg 41(1): 63-70.

18. Couldwell SM, Kraus KL, Couldwell WT (2011) Regression of cerebral arteriovenous malformation in the puerperium. Acta Neurochir (Wien) 153(2): 359-362.

19. Schwartz J, Lynbrook NY (1951) Pregnancy complicated by subarachnoid hemorrhage. Am J Obstet Gynecol 62(3): 539-547.

20. Newton CL, Bell SD (1995) Arteriovenous malformation in the pregnant patient: a case study. J Neurosci Nurs 27(2): 109-112.

21. Redekop G, TerBrugge K, Montanera W, Willinsky R (1998) Arterial aneurysms associated with cerebral arteriovenous malformations: classification, incidence, and risk of hemorrhage. J Neurosurg 89(4): 539-546.

22. English LA, Mulvey DC (2004) Ruptured arteriovenous malformation and subarachnoid hemorrhage during emergent cesarean delivery: a case report. AANA J 72(6): 423-426.

23. Priya S, Nelson C, Heli T, Mebazaa A (2016) Physiologic changes in pregnancy. Cardiovasc J Afr 27(2): 89-94.

24. Motosko C, Bieber A, Pomeraz M, Stein JA, Martires KJ, et al. (2017) Physiologic changes of pregnancy: a review of the literature. Int J Womens Dermatol 3(4): 219-224. 
25. Sanghavi M, Rutherford J (2014) Cardiovascular physiology of pregnancy. Circulation 130(12): 1003-1008.

26. Kimelberg HK (2004) Water homeostasis in the brain: basic concepts. Neuroscience 129(4): 851-860.

27. Euser AG, Cipolla MJ (2007) Cerebral blood flow autoregulation and edema formation during pregnancy in anesthetized rats. Hypertension 49(2): 334-340.

28. Cipolla MJ (2007) Cerebrovascular function in pregnancy and eclampsia. Hypertension 50(1): 14-24.

29. Zeeman GG, Hatab M, Twickler DM (2003) Maternal cerebral blood flow changes in pregnancy. Am J Obstet Gynecol 189(4): 968-972.

30. Hinojosa A, Gulati M, Singh V (2003) Spontaneous intracerebral hemorrhage due to coagulation disorder. Neurosurg Focus 15(4): E3.

31. Broderick JP, Brott T, Tomsick T, Miller R, Huster G, et al. (1993) Intracerebral hemorrhage more than twice as common as subarachnoid hemorrhage. J Neurosurg 78(2): 188-191.

32. Cordonnier C, Demchuk A, Ziai W, Anderson CS (2018) Intracerebral haemorrhage: current approaches to acute management. Lancet 392(10154): 1257-1268.

33. Stein M, Misselwitz B, Hamann GF, Scharbrodt W, Schummer DI, et al. (2012) Intracerebral hemorrhage in the very old: future demographic trends of an aging population. Stroke 43(4): 1126-1128.

34. Flaherty ML, Woo D, Haverbusch M, Sekar P, Khoury J, et al. (2005) Racial variations in location and risk of intracerebral hemorrhage. Stroke 36(5): 934-937.

35. Garcia JH, Ho KL (1992) Pathology of hypertensive arteriopathy. Neurosurg Clin N Am 3(3): 497-507.

36. Arima H, Anderson CS, Wang JG, Huang Y, Heeley E, et al. (2010) Intensive Blood Pressure Reduction in Acute Cerebral Haemorrhage Trial Investigators. Lower treatment blood pressure is associated with greatest reduction in hematoma growth after acute intracerebral hemorrhage. Hypertension 56(5): 852-858.

37. Morgenstern LB, Hemphill JC, Anderson C, Becker K, Broderick JP, et al. (2010) Guidelines for the management of spontaneous intracerebral hemorrhage: a guideline for healthcare professionals from the American Heart Association/American Stroke Association. Stroke 41(9): 2108-2129.

38. Schwarz S, Häfner K, Aschoff A, Schwab S (2000) Incidence and prognostic significance of fever following intracerebral hemorrhage. Neurology 54(2): 354-361.
39. ICRP (2000) Pregnancy and medical radiation. Ann ICRP 30(1): ii-viii, $1-43$.

40. Smith FW, Adam AH, Phillips WD (1983) NMR imaging in pregnancy. Lancet 1: 61-62.

41. Almeida JP, Medina R, Tamargo RJ (2015) Management of posterior fossa arteriovenous malformations. Surg Neurol Int 6: 31.

42. Spetzler RF, Martin NA (1986) A proposed grading system for arteriovenous malformations. J Neurosurg 65(4): 476-483.

43. Viñuela F, Dion JE, Duckwiler G, Martin NA, Lylyk P, et al. (1991) Combined endovascular embolization and surgery in the management of cerebral arteriovenous malformations: experience with 101 cases. J Neurosurg 75(6): 856-864.

44. Robinson JL, Hall CS, Sedzimir CB (1974) Arteriovenous malformations, aneurysms and pregnancy. J Neurosurg 41(1): 63-70.

45. Finnerty JJ, Chisholm CA, Chapple H, Login IS, Pinkerton JV, et al. (1999) Cerebral arteriovenous malformation in pregnancy: presentation and neurologic, obstetric and ethical significance. Am J Obstet Gynecol 181(2): 296-303.

46. Dammann P, Asgari S, Bassiouni H, Gasser T, Panagiotopoulos V, et al. (2011) Spontaneous cerebellar hemorrhage--experience with 57 surgically treated patients and review of the literature. Neurosurg Rev 34(1): 77-86.

47. Yanaka K, Meguro K, Fujita K, Narushima K, Nose T, et al. (1999) Postoperative brainstem high intensity is correlated with poor outcomes for patients with spontaneous cerebellar hemorrhage. Neurosurgery 45(6): 1323-1327.

48. Ott KH, Kase CS, Ojemann RG, Mohr J (1974) Cerebellar hemorrhage: diagnosis and treatment. A review of 56 cases. Arch Neurol 31(3): 160167.

49. Arnaout OM, Gross BA, Eddleman CS, Bendok BR, Getch CC, et al. (2009) Posterior fossa arteriovenous malformations. Neurosurg Focus 26(5): E12.

50. Agarwal N, Guerra JC, Gala NB, Agarwal P, Zouzias A, et al. (2014) Current treatment options for cerebral arteriovenous malformations in pregnancy: a review of the literature. World Neurosurg 81(1): 83-90.

51. Liu XJ, Wang S, Zhao YL, Teo M, Guo P, et al. (2014) Risk of cerebral arteriovenous malformation rupture during pregnancy and puerperium. Neurology 82(20): 1798-1803.

\section{Your next submission with Juniper Publishers} will reach you the below assets

- Quality Editorial service

- Swift Peer Review

- Reprints availability

- E-prints Service

- Manuscript Podcast for convenient understanding

- Global attainment for your research

- Manuscript accessibility in different formats

( Pdf, E-pub, Full Tsext, Audio)

- Unceasing customer service

Track the below URL for one-step submission https://juniperpublishers.com/online-submission.php 